\title{
First report of Fusarium wilt of watermelon in Vietnam
}

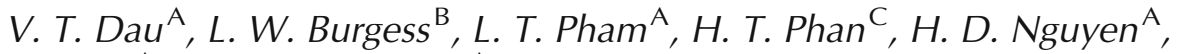 \\ T. V. Le $e^{\mathrm{A}}$ and D. H. Nguyen ${ }^{\mathrm{A}}$

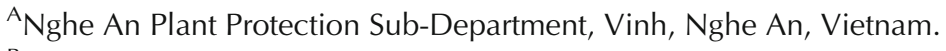 \\ ${ }^{B}$ Faculty of Agriculture, Food and Natural Resources, The University of Sydney, NSW 2006, Australia. \\ ${ }^{\mathrm{C}}$ National Institute of Medicinal Materials, Hanoi, Vietnam. \\ DCorresponding author. Email: I.burgess@usyd.edu.au
}

\begin{abstract}
Fusarium wilt of watermelon caused by Fusarium oxysporum $\mathrm{f}$. sp. niveum caused seedling losses in nurseries, as well as severe losses in many crops in Nghe An province, Vietnam, in 2008. Isolates of the fungus were shown to be pathogenic. All 20 cultivars grown in the province in 2008 were susceptible. This is the first formal report of this disease in Vietnam.
\end{abstract}

Watermelon production is a relatively new industry in Nghia Dan district, Nghe An province, Vietnam. The area under production is $\sim 500$ ha. Individual crops vary in area from $\sim 0.2-2$ ha. Crops are grown in spring, in furrows from transplants, with some farmers using a plastic mulch. A hose is used to water each furrow and the water can run along the furrow depending on the slope. In some fields the bottom of the furrow is terraced with small check banks to pond water around the plant during watering. Soils vary from well drained alluvial soils along the river to heavier clay loam soils on undulating upland areas away from the river. The transplants are grown in small plastic bags, placed partly in the soil, in field beds (Fig. 1). Watermelons are commonly grown in the same field each year. District staff of the Plant Protection Sub-Department (PPSD) of Nghe An noted serious losses from damping-off of seedlings and wilt disease in 2007 but diagnostic studies were not undertaken. In spring 2008 damping-off in nurseries (Figs 1 and 2), and wilting of young plants in the field occurred again, following a period of cool

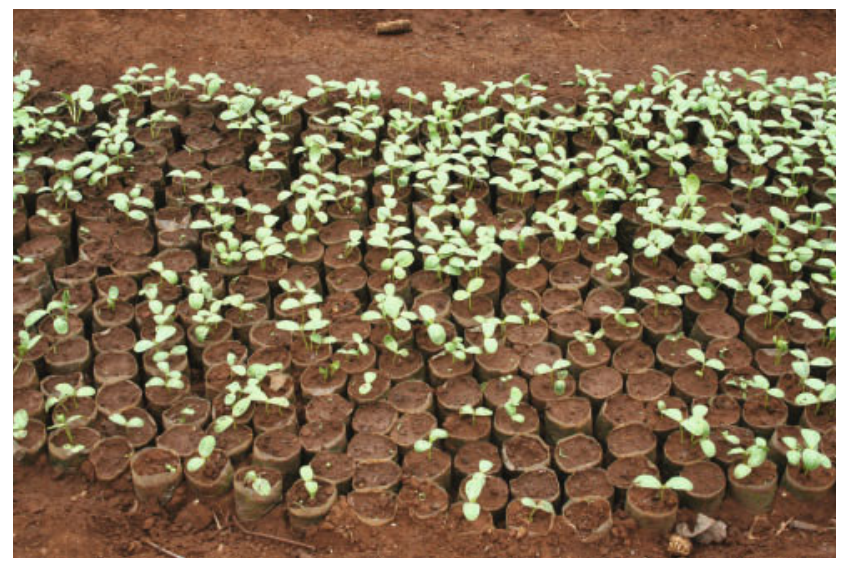

Fig. 1. A watermelon nursery affected by damping-off of seedlings. wet weather. During this period the air temperatures varied daily from $\sim 10$ to $20^{\circ} \mathrm{C}$.

Preliminary observations indicated that several fungal pathogens, including the Fusarium wilt pathogen, Fusarium oxysporum f. sp. niveum (Zitter et al. 1996), were responsible for seedling losses. Field observations also indicated that Fusarium wilt was the likely cause of wilting of young crop plants (Figs 3 and 4) as they were not affected by root, collar or stem rots. Consequently an ad hoc survey of damping-off in nursery seedlings was undertaken on 14 March to assess the symptoms and collect samples for diagnostic purposes. Six nurseries, representative of nurseries in the district, were surveyed. Ten seedlings affected by damping-off were collected on an ad hoc basis from each nursery and stored in paper bags in a cool box for transport to the laboratory. Dead seedlings were not collected. There was no damping-off in Nursery 6, where field soil from an area with no history of

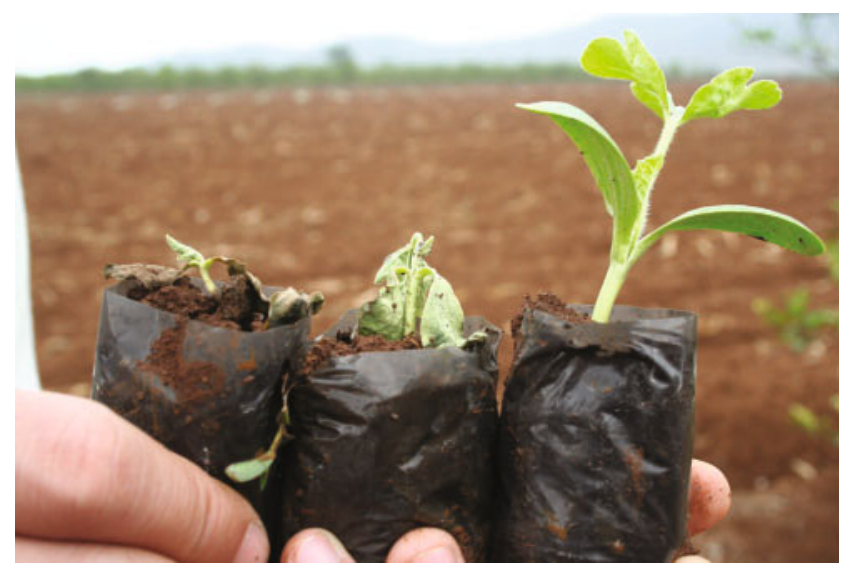

Fig. 2. Watermelon seedlings with wilt symptoms typical of Fusarium wilt, left and centre, with a symptomless seedling on right. 


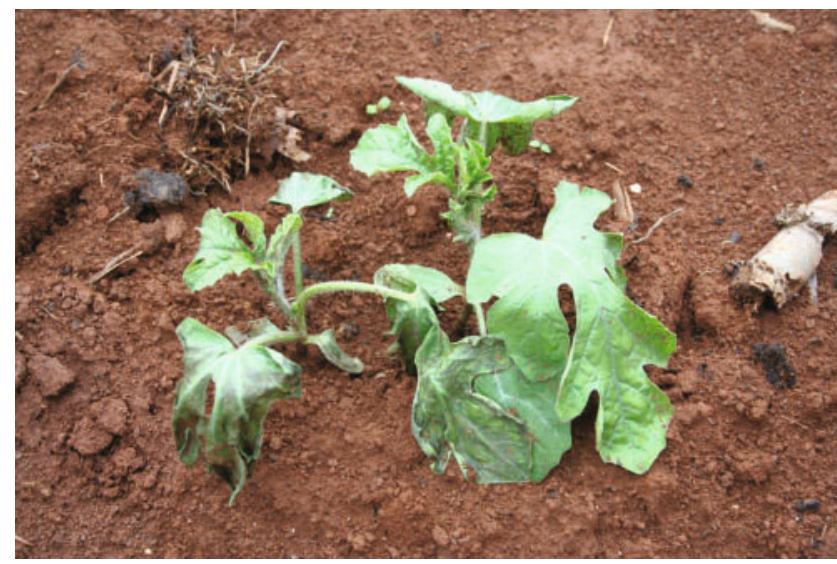

Fig. 3. Watermelon plant affected by Fusarium wilt on left, symptomless plant on right.

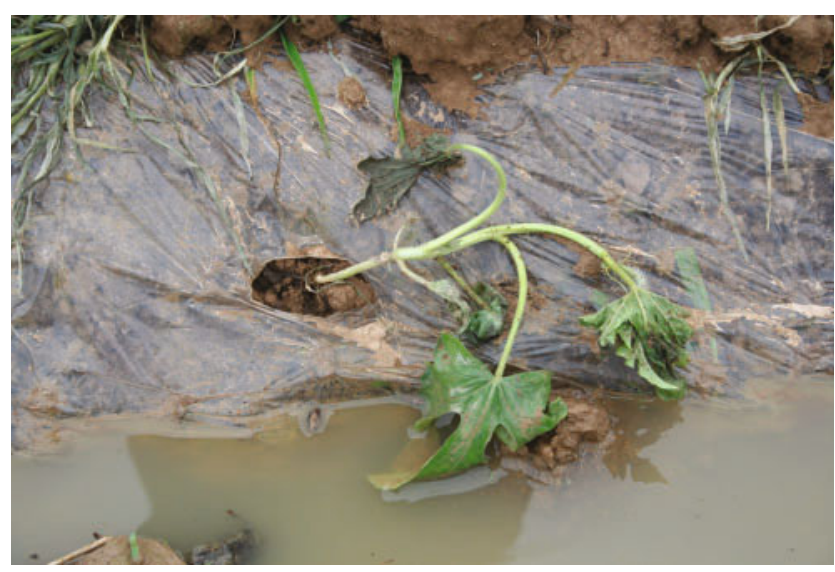

Fig. 4. Watermelon plant showing wilt symptoms caused by Fusarium wilt, growing in very wet conditions.

watermelons had been used. In addition three surveys of putative Fusarium wilt in watermelon crops were undertaken to collect samples for diagnostic purposes on 14 and 26 March, and 28 April.

Seedlings were washed in tap water and examined. The hypocotyls of some seedlings were affected by a collar rot typical of infection by Rhizoctonia spp. or Sclerotium rolfsii. Other seedlings were affected by a wet rot of the roots and hypocotyl, a symptom more typical of Pythium damping-off (Burgess et al. 2008). The remaining seedlings were wilting but had none of the above symptoms or vascular discolouration, and were assumed to be affected by Fusarium wilt (Fig. 2). The hypocotyl was removed from each seedling, surface sterilised in $70 \%$ ethyl alcohol for $5 \mathrm{~s}$, immediately rinsed in sterile water and damp-dried on sterile paper tissue. A 2-3 mm length of hypocotyl at the margin of diseased and symptomless tissue was then removed aseptically and plated on water agar containing streptomycin sulfate $(1.0 \mathrm{~g} / \mathrm{L})$ and neomycin sulfate $(0.12 \mathrm{~g} / \mathrm{L})$. A $2-3 \mathrm{~mm}$ segment was also removed from the hypocotyl of seedlings with no obvious symptoms and plated as above. Plates were incubated under $12: 12 \mathrm{~h}$ dark: ultraviolet/ fluorescent light, at $\sim 25^{\circ} \mathrm{C}$. Fungal colonies developed from the segments within $48 \mathrm{~h}$. Each colony was sub-cultured to potato dextrose agar (PDA) for preliminary identification to genus. The detailed results of these isolation studies will be reported separately. A putative colony of $F$. oxysporum developed from one seedling from Nursery 2, a wilted seedling with no obvious rot of the hypocotyl or roots. Some putative colonies of $F$. oxysporum were also observed developing from other segments but were overgrown by fast-growing colonies identified putatively as Rhizoctonia, S. rolfsii, or Pythium, and were not recovered. The putative culture of $F$. oxysporum was transferred to carnation leaf piece agar (CLA) and PDA using the single spore technique (Burgess et al. 2008) grown under lights as described above for 2 weeks, before morphological identification.

Wilted plants collected from watermelon crops were washed and examined for other symptoms including vascular browning; however, there were no other obvious symptoms. A 1-cm segment of the stem $5 \mathrm{~cm}$ above the crown was removed and surface sterilised as described above. Two 1-mm-thick transverse sections were then excised aseptically and plated with the cut surface pressed firmly onto the agar of the isolation medium described above. Hyphae forming monophialides and falseheads of microconidia typical of $F$. oxysporum (Burgess et al. 2008) were observed growing from the xylem vessels of all stem segments from the three surveys after $24 \mathrm{~h}$, using a stereomicroscope. The colonies that subsequently developed on the agar were subcultured, purified and identified (Burgess et al. 2008). All colonies were identified morphologically as F. oxysporum (Burgess et al. 2008). The consistent isolation of this species indicates that it was the cause of the wilt disease observed in the field.

The isolate of $F$. oxysporum from the seedling from Nursery 2 and four isolates of $F$. oxysporum from crop plants caused wilting and death of plants in a preliminary test of pathogenicity using a stem inoculation technique (Burgess et al. 2008). The isolate from the wilted seedling was also tested for pathogenicity using an inoculated soil technique following the methods in Dau et al. (2008). The inoculum was prepared by growing the isolate in a millet/rice hull medium (Burgess et al. 2008). The inoculum was added at $10 \%$ by volume to a potting mix consisting of river sand and sterile rice hulls, 9:1, v/v. The inoculated mix was placed in $25-\mathrm{cm}$-diameter pots. Five watermelon seeds, cv. Hac My Nhan, one of the cultivars affected by wilt in the field, were planted on the inoculated soil in each pot. A 2-cm layer of non-inoculated soil mix was then added over the seeds. The pots were placed in the sun and maintained at approximately field capacity by sprinkling with tap water every 3 days. The air temperatures varied daily from $\sim 18^{\circ} \mathrm{C}$ to $28^{\circ} \mathrm{C}$. There were three inoculated pots and three non-inoculated control pots.

Typical wilt symptoms developed in five of the plants inoculated with the isolate of $F$. oxysporum by day 20, the two main-leaf stage, and by day 40 all plants had wilted and died. None of the wilted plants developed vascular browning. The control plants did not develop symptoms. It is concluded that the pathogen is $F$. oxysporum f. sp. niveum (Zitter et al. 1996). Two isolates have been preserved in the culture collection at the Nghe An PPSD as accession numbers NA54 and NA55. 
Vascular discoloration was not observed in wilted plants in the field or in the pathogenicity tests. It is noteworthy that wilt symptoms developed in infected plants growing in saturated soil (Fig. 3). It is possible that the pathogen was producing a toxin such as fusaric acid that inhibited root function and the uptake of water (Wu et al. 2008). All of the 20 cultivars grown in 2008 were susceptible. The high incidence of Fusarium wilt in some fields can be attributed to regular cropping with watermelons and the common practice of raising seedlings in soil from infested fields. The furrow irrigation practices would also favour dispersal of inoculum of the pathogen within fields. The rapid increase in the incidence and severity of the disease is illustrated by the estimates of the area with $100 \%$ loss in 2006 , 2007 , and 2008 being 0,1 and 66 ha respectively, based on annual disease surveys of diseases in watermelon by PPSD district staff. As many formae speciales of $F$. oxysporum are known to persist in soil for many years as chlamydospores (Burgess et al. 2008), and by colonising the cortex of roots of non-host plants (Hendrix and Nielson 1958), this pathogen is likely to persist in infested fields for many years, even in the absence of susceptible watermelon crops.

The use of pathogen-free transplants in fields with no history of watermelon could be a reasonable disease management strategy in the short-term. The use of watermelon seedlings grafted onto resistant cucurbit rootstocks has been promoted for the control of Fusarium wilt in watermelon (Boughalleb et al. 2007). The feasibility of using this strategy in Nghe An is being assessed. This is the first report of Fusarium wilt of watermelon in Nghe An province and in Vietnam.

\section{Acknowledgements}

The authors gratefully acknowledge the Australian Centre for International Agricultural Research for financial support, Mr Thieu, Director Nghe An PPSD for advice and support, and Syngent ${ }^{\circledR}$ for the provision of seed of resistant rootstocks.

\section{References}

Boughalleb N, Tarchoun N, El Mbarki A, El Mahjoub M (2007) Resistance Evaluation of Nine Cucurbit Rootstocks and Grafted Watermelon (Citrullus lanatus L.) Varieties Against Fusarium Wilt and Fusarium Crown and Root Rot. Journal of Plant Sciences 2, 102-107.

Burgess LW, Knight TE, Tesoriero L, Phan HT (2008) Diagnostic manual for plant diseases in Vietnam. ACIAR Monograph No 129. (Australian Centre for International Agricultural Research: Canberra).

Dau VT, Tran CV, Pham LT, Phan HT, Dang HL, Burgess LW (2008) Stem and root rot of Telosma cordata caused by Phytophthora palmivora in Vietnam - a newly recognised disease. Australasian Plant Disease Notes 3, 135-137.

Hendrix FF Jr, Nielson LW (1958) Invasion and infection of crops other than the forma suscept by Fusarium oxysporum f. batatas and other formae. Phytopathology 48, 224-228.

Wu HS, Yin XM, Liu DY, Ling N, Bao W, Ying RR, Zhu YY, Guo SW, Shen QR (2008) Inhibition of root cell transmembrane potential and leaf anti-stress enzymes of watermelon seedlings by fusaric acid. Scientia Agricultura Sinica 41, 2641-2650.

Zitter TA, Hopkins DL, Thomas CE(1996) Compendium of cucurbit diseases. (The American Phytopathological Society Press: St Paul, MN.)

Manuscript received 9 January 2009, accepted 16 January 2009 